\title{
Regulation of Dopamine Production by Genetically Modified Primary Fibroblasts
}

\author{
Un Jung Kang, ${ }^{1}$ Lisa J. Fisher, ${ }^{1}$ Tong H. Joh, ${ }^{2}$ Karen L. O'Malley, ${ }^{3}$ and Fred H. Gage ${ }^{1}$ \\ 'Department of Neurosciences, University of California at San Diego, La Jolla, California 60638-0627, \\ 'Laboratory of Molecular Neurobiology, Burke Medical Research Institute, White Plains, New York 10605, and \\ ${ }^{3}$ Department of Anatomy and Neurobiology, Washington University, St. Louis, Missouri 63110
}

Primary skin fibroblasts were genetically modified with catecholamine-synthesizing enzyme genes and studied as potential syngeneic donor cells to supply catecholamines in animal models of Parkinson's disease. Primary skin fibroblasts obtained from inbred Fischer 344 rats were transduced with tyrosine hydroxylase (TH) or aromatic L-amino acid decarboxylase (AADC) CDNAs using retroviral vector system. The transduced cells were characterized in vitro by enzymatic assay, immunocytochemistry, and HPLC analysis of catecholamine production and release. Accumulation of high levels of dopamine was detected in the media in a timedependent manner. Secretion of dopamine and its metabolites appeared to be constitutive without significant storage capacity in vesicles or regulation at the level of secretion. The feasibility of regulating the final dopamine production by the AADC-transduced cells was explored in two ways. First, administration of various doses of the precursor, L-dopa, resulted in a controlled production of dopamine by these cells. Second, coculturing AADC-transduced cells with THtransduced cells in various proportions allowed control of dopamine production. TH-transduced cells served as an endogenous source of precursor. We propose the use of these cells to study the role of AADC in restoring the dopaminedeficient behavior and to compare the effect of dopamineproducing cells with L-dopa-producing cells either by cografting TH-transduced cells with AADC-transduced cells or by grafting TH-transduced cells alone. The role of AADC in vivo will be assessed in future experiments involving animal models of Parkinson's disease.

[Key words: aromatic L-amino acid decarboxylase (AADC), genetically modified cells, fibroblast, Parkinson's disease, tyrosine hydroxylase, transplantation, dopa decarbaxylase, dopamine, 3,4-dihydroxy-L-phenylalanine (L-dopa), gene therapy, retroviral vector]

\footnotetext{
Received Dec. 17, 1992; revised Apr. 26, 1993; accepted June 10, 1993.

This work was supported by U.S. Public Health Science Grants AG00408, AG08514, and AG109435, and an American Academy of Neurology Research Fellowship. We thank Regina Wu, Lynn Moore, Barbara Mason, and Steven Forbes for their technical assistance, Dr. P. J. Langlais for his help with HPLC analysis, and Mary Lynn Gage for her helpful comments on the manuscript. The authors would like to acknowledge Michael B. Rosenberg for construction of TH factor when at Genesys Inc., and Hyder A. Jinnah and Michael B. Rosenberg for construction of the DDC factor at the Department of Pediatrics, UCSD, in Dr. P. Friedman's lab.

Correspondence should be addressed to Un Jung Kang, M.D., Department of Neurology, The University of Chicago, MC 2030, 5841 South Maryland Avenue, Chicago, IL 60637.

Copyright (c) 1993 Society for Neuroscience $0270-6474 / 93 / 135203-09 \$ 05.00 / 0$
}

Parkinson's disease (PD) is a progressive neurodegenerative disorder characterized by the loss of dopaminergic cells in the substantia nigra and other neurons in pigmented nuclei (Jellinger, 1987). Treatment strategies aimed at replacement of the missing neurotransmitter dopamine have worked well and remain the prototypic examples of symptomatic treatment for neurodegenerative disorders (Cotzias et al., 1969). Since the neurotransmitter dopamine does not cross the blood-brain barrier, the precursor, 3,4-dihydroxy-L-phenylalanine (L-dopa), is given orally. L-dopa is subsequently converted into the final neurotransmitter dopamine by aromatic L-amino acid decarboxylase (AADC) in the CNS. Administration of L-dopa with peripheral AADC inhibitor has been the mainstay of therapy for PD in attenuating many of the motor symptoms (Marsden and Parkes, 1977).

However, long-term treatment often leads to fluctuating response, dyskinesias, and psychiatric symptoms (Sweet et al., 1976; Nutt, 1990). Some of these problems can be controlled by continuous delivery of dopamine agonists using duodenal (Kurlan et al., 1988) or intravenous infusions (Quinn et al., 1986), but these infusion methods are not realistic for long-term therapy. Moreover, this type of systemic delivery cannot avoid stimulation of the dopaminergic system in other arcas, resulting in development of untoward symptoms such as psychosis. Continuous delivery of dopamine localized to the target area of the striatum may serve to alleviate and prevent many of the longterm complications of the presently available pharmacological treatments. Transplantation of cells and tissues producing dopamine has been explored as a means of providing such a delivery system. Experiments utilizing fetal substantia nigra neurons in rats with experimental dopamine depletion have shown good survival of the grafts and functional effects in restoring dopamine-deficient behavior (Dunnett et al., 1988). However, the use of fetal donor tissue transplants in patients raises ethical and political questions as well as the practical issue of harvesting enough healthy tissue for grafting. Therefore, various alternative cells and tissues that produce catecholamine have been studied for grafting in the striatum.

Immortalized cell lines have the advantage of casy availability but often form tumors after grafting or are rejected by the host (Freed et al., 1986). Autologous tissues producing catecholamines such as adrenal medulla have been explored as a donor tissue since immune responses can be minimized by use of syngeneic tissues, but the survival of adrenal medulla in the brain has been poor (Fine, 1990; Freed et al., 1990). Therefore, one of the more promising and potentially versatile approaches 


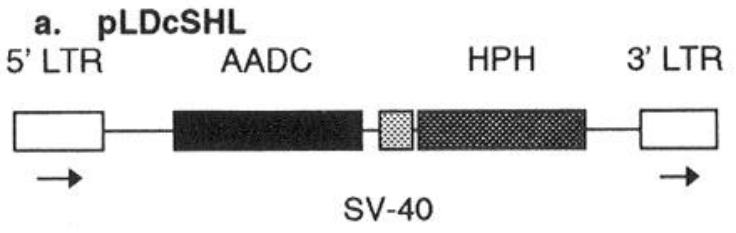

b. PLhTHRNL

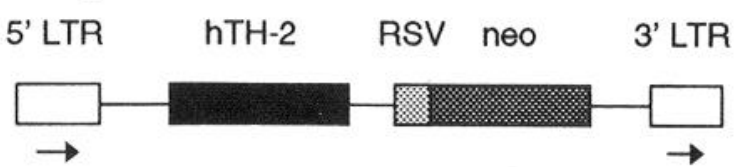

Figure 1. The schematic representation of LDcSHL and LhTHRNL plasmids. $a$, The $1.6 \mathrm{~kb}$ EcoRI-NcoI fragment of bovine AADC cDNA $(A A D C)$ was inserted downstream from the $5^{\prime}$ retroviral long-term repeat $(L T R)$. The selectable marker hygromycin-B-phosphotransferase $(H P H)$ is under the control of an internal simian virus-40 early promoter $(S V-40) . b$, Human TH type II cDNA $(h T H-2)$ is subcloned in a vector with aminoglycoside phosphotransferase (neo) expressed from an internal Rous sarcoma virus (RSV) promoter. The arrows under the viral LTRs show the direction of transcription.

to the transplant problem is the use of genetically modified primary cells (Gage et al., 1991a,b). The use of primary cultures of cells obtained from a biopsy from the host or from syngeneic subjects minimizes immunological responses of the host to the graft. The methods of primary cell culture and gene transfer have been well established in skin fibroblast systems. The longterm survival of primary skin fibroblast cells after grafting into the CNS has been well documented by light microscopic and ultrastructural studies (Kawaja and Gage, 1992). This system, then, serves as a biological delivery pump for neurotransmitters (Gage, 1990). The utility of the system is twofold: first, it provides a potential therapeutic modality for continuous and localized delivery of neurotransmitters and other biologically active molecules; second, this approach provides an ideal experimental system in which the role of a particular neurotransmitter or neurotrophic factor can be studied in vivo, since the only difference between the experimental group and the control group is the presence of a single gene transduced into the primary cells.

This system of genetically modified donor cells has been used previously to transduce cells with tyrosine hydroxylase (TH) to produce L-dopa from endogenous tyrosine available within the cells. Recovery of rotational behavioral abnormalities in animal models of PD with unilateral substantia nigra lesions has been achieved by grafting genetically modified cell lines (Horellou et al., 1990b) and primary cells (Fisher et al., 1991). Production of L-dopa and dopamine in vivo by genetically modified cell lines was also noted (Horellou et al., 1990a). However, production of L-dopa by the graft might not be as efficient as production of dopamine itself in reversing the dopamine-deficient behaviors. AADC is the necessary step in completing this process. The amount of dopamine delivered by these grafts is also critical in the final functional outcome. Therefore, in this article we describe genetic modification of skin fibroblast cells with AADC and characterize their biochemical properties in production of dopamine. We also explore two approaches for regulating final dopamine production by these cells transduced with AADC: one with exogenous precursor administration and the other with endogenous precursor production by coculturing with cells transduced with TH.

\section{Materials and Methods}

Retroviral vector construction. Retroviral vector was derived from Moloney murine leukemia virus. The structural genes $\mathrm{gag}$, pol, and env were replaced by the selectable marker hygromycin-B-phosphotransferase (HPH), which is under the control of an internal simian virus40 (SV-40) early promoter $(\Delta \mathrm{H}$; a gift from Dr. Robert Overell at Immunex). The 1.6 kilobase (kb) EcoRI-NcoI fragment containing the full coding region and a part of the 3 ' untranslated region of bovine AADC cDNA (Kang and Joh, 1990) was ligated into the vector $\Delta H$ downstream from the viral 5 ' long terminal repeat (LTR) (LDcSHL: Fig. 1a). The plasmid LDcSHL was transfected into the PA317 amphotropic packaging line (Miller and Buttimore, 1986) using the calcium phosphate precipitation procedure (Graham and Van Der Eb, 1973). Conditioned medium was collected and used to infect the ecotropic cell line $\Psi-2$ (Mann et al., 1983). Clones of $\Psi-2$ cells were selected in the presence of $400 \mu \mathrm{g} / \mathrm{ml}$ of hygromycin-B and the conditioned medium was used to infect Rat 1 cell line to assay for virus titer. Two $\Psi-2$ viral producer clones with the highest viral titers $\left(5 \times 10^{4}\right.$ plaque-forming units $\left./ \mathrm{ml}\right)$ were assayed for AADC activity as described below. Both of these clones were used to infect primary skin fibroblast cells. The $1.9 \mathrm{~kb}$ EcoRIEcoRI fragment containing the full coding region of human TH type II cDNA was subcloned into a similar retroviral vector containing aminoglycoside phosphotransferase (neo) expressed from an internal Rous sarcoma virus promoter. The recombinant retrovirus containing $\mathrm{TH}$ (LhTHRNL: Fig. $1 b$ ) was used to transduce viral producer cells, and the transduced cells were selected in the presence of $400 \mu \mathrm{g} / \mathrm{ml}$ of G418.

Primary cultures of dermal fibroblasts. Skin biopsies were obtained from inbred Fischer 344 rats for primary cultures of dermal fibroblasts as described before (Fisher et al., 1991). Fibroblasts were grown in Dulbecco's modified Eagle's medium (DMEM) supplemented with $10 \%$ fetal bovine serum, $0.3 \mathrm{mg} / \mathrm{ml}(2 \mathrm{~mm})$ of glutamate, $2.5 \mu \mathrm{g} / \mathrm{ml}$ of amphotericin, and $40 \mu \mathrm{g} / \mathrm{ml}$ of gentamicin. When cells reached confluence, they were passaged by trypsinization, resuspended, and replated. Primary skin fibroblasts were grown in vitro with a doubling time of approximately $2.5 \mathrm{~d}$ when passaged 1:4 dilution after confluence. Passage number was carefully monitored. Primary fibroblasts were infected with the AADC-containing retrovirus by incubating them in the conditioned medium from the packaging cell lines in $4 \mu \mathrm{g} / \mathrm{ml}$ of polybrene. The multiplicity of infection was $1: 1$. The following day, the medium was replaced with the modified DMEM described above with $150 \mu \mathrm{g} / \mathrm{ml}$ of hygromycin B for the AADC-transduced cells (FF/AADC) and $400 \mu \mathrm{g}$ $\mathrm{ml}$ of G418 for TH-transduced cells (FF/TH). When the infected cells were selected in the presence of hygromycin B, initially only a small fraction of cells survived and grew to confluence by about 2-3 weeks. Surviving fibroblasts were grown to confluence and further expanded by passaging them. For comparison, clones were selected from surviving fibroblasts for further expansion. Since transgene enzyme activities of clones were comparable to bulk-infected batch of cells, all the experiments were performed with a bulk-infected batch of cells that were grown to confluence after selection, without picking out individual clones. These bulk-infected clones were then passaged subsequently to multiply for in vitro analyses and grafting. Use of bulk-infected cells rather than a clonal population allowed less doubling time in culture before enough cells could be harvested for grafting. All of the in vitro and in vivo experiments were carried out in cells between passages 8 and 14. However, even at a passage as high as 24 , the cell growth and morphology in vitro remained stable with contact inhibition.

Biochemical assays. AADC activity was assayed with a modification of a $\mathrm{CO}_{2}$ trapping procedure in the presence of ${ }^{14} \mathrm{C}$-labeled DL-dopa and $10 \mu \mathrm{M}$ pyridoxal $5^{\prime}$-phosphate (PLP) (Lamprecht and Coyle, 1972). The reaction mixtures were placed in the microwells and covered with a filter soaked in NCS (Amersham) or methylbenzethonium hydroxide (Sigma). The microwell and the filter were placed in the airtight holder (Transys Inc.) (Bostwick and Le, 1991). Following a 20-min incubation at $37^{\circ} \mathrm{C}$, the reaction was stopped by raising the temperature to $60^{\circ} \mathrm{C}$. The ${ }^{14} \mathrm{C}-\mathrm{CO}_{2}$ was trapped on a filter soaked in tissue solubilizer during a $60 \mathrm{~min}$ postincubation period at $37^{\circ} \mathrm{C}$. The radioactivity was measured by scintillation counting. The TH activity assay measures the conversion of ${ }^{14} \mathrm{C}$-tyrosine to $\mathrm{L}$-dopa in the presence of 6 -methyltetrahydropterin at $37^{\circ} \mathrm{C}$ for $1 \mathrm{hr}$. The $\mathrm{L}$-dopa is subsequently converted to dopamine and ${ }^{14} \mathrm{C}-\mathrm{CO}_{2}$ in the presence of excess AADC to achieve near total 
conversion of $\mathrm{L}$-dopa to ${ }^{14} \mathrm{C}-\mathrm{CO}_{2}$ (Waymire et al., 1971). For both assays kinetic data were obtained by varying concentrations of precursors and cofactors.

Northern blot analysis. Fibroblasts were seeded onto a $10 \mathrm{~cm}$ tissue culture plate and allowed to reach $70-80 \%$ confluence. Cells were washed in phosphate-buffered saline and total RNA was isolated by extracting the cells in guanididium isothiocyanate solution. The amount of total RNA was quantified by measuring absorbance at $260 \mathrm{~nm}$. Each sample was loaded in two lanes with 5 and $20 \mu \mathrm{g}$ of total RNA onto a $1.2 \%$ formaldehyde-agarose gel. Separated RNA was blotted onto nylon membranes (Sambrook et al., 1989). Blots were prehybridized for 1-2 $\mathrm{hr}$ and denatured radiolabeled probes ( 795 base pair EcoR 1-Apal fragment of bovine AADC cDNA) were added directly to the blot. Following hybridization, the blot was washed several times and then wrapped in plastic film for autoradiography. After hybridization with AADC cDNA probe, the blot was stripped and rehybridized with a probe for cyclophilin as a standard. Quantitative estimation of the message amount was obtained by scanning a radiograph (Kodak XRA film) at a linear range exposure for densitometry (StradaScan 7000 system, Stratagene Cloning Systems). Radiographs were exposed for various duration from 3 to $72 \mathrm{hr}$ to the hybridized blot to determine the linear range.

Immunohistochemical staining. Control and transduced fibroblasts were grown on chamber slides (Tissue Tek), fixed with $4 \%$ phosphatebuffered paraformaldehyde, and permeabilized with $0.2 \%$ Triton X-100. Cells were labcled immunohistochemically with an anti-bovine AADC polyclonal antibody raised in rabbits at 1:15,000 dilution (Jeager et al., 1984) or anti-rat TH monoclonal antibody at 1:200 dilution (Boehringer-Mannheim). The antigen-antibody complex was reacted with a goat anti-rabbit antibody attached to biotin. Staining was developed by the avidin-biotin method with nickel intensification using 3,3'-diethylamidobenzidine as the chromagen (Vector Laboratories, Elite Kit).

Dopamine production in culture. Transduced cells were grown in the modified DMEM with a selection agent and passaged 1:4 after reaching confluence. Production of catecholamines were examined by incubating cells at $100 \%$ confluence with proper precursors and cofactors in the modified DMEM described above and $0.01 \%$ ascorbic acid. Unmodified DMEM contains $398 \mu \mathrm{M}$ L-tyrosine and $24 \mu \mathrm{M}$ pyridoxal $\mathrm{HCl}$. For FF/ TH cells, the modified DMEM was supplemented with $100 \mu \mathrm{MBH}$ For FF/ $\Lambda \Lambda D C$ cells, various concentrations of $L-d o p a(0-500 \mu \mathrm{M})$ were added to the modified DMEM. For time course study, conditioned media and cells were collected at various times after incubation from 0 to $24 \mathrm{hr}$. Conditioned media and cells were collected separately and adjusted to $0.1 \mathrm{~m}$ perchloric acid (PCA) and $5 \mathrm{~mm}$ EDTA and then centrifuged at $10,000 \times g$ for $15 \mathrm{~min}$ at $4^{\circ} \mathrm{C}$ to remove precipitated material. The samples were analyzed for the presence of catecholamines and catecholamine metabolites by injection of the PCA extract onto a coulometric electrode array, gradient liquid chromatography system (CEAS model 55-0650, ESA, Bedford, MA), equipped with 16 electrochemical sensors and a refrigerated autosampler.

Coculture of $F F / T H$ and $F F / A A D C$. FF/TH cells and FF/AADC cells were harvested and mixed at different ratios from 10:1 to $1: 10$. A total of $2 \times 10^{5}$ cells was replated in each well in the modified DMEM. They were incubated overnight to allow attachment of cells to the plate and were incubated in the modified DMEM with $100 \mu \mathrm{M} \mathrm{BH}_{4}$. Media were collected as above and the cells were harvested separately to measure catecholamine levels by HPLC.

\section{Results}

Transduction of primary skin fibroblasts

The AADC activities of two $\Psi-2$ clones with the highest titers were $11.2 \mathrm{nmol} / \mathrm{mg} / \mathrm{min}$ for clone 9 and $1.6 \mathrm{nmol} / \mathrm{mg} / \mathrm{min}$ for clone 21 . Infection of fibroblasts from several different biopsies with these two different clones of the viral producer lines produced comparable AADC activitics in all cascs. Rat 1 cells were also infected with the recombinant retrovirus containing AADC cDNA and showed comparable enzymatic activities. Some of the examples of transduced primary fibroblast cells are listed in Table 1; enzymatic activities of these cells were comparable to those of rat caudate. Examination of the kinetic properties of the recombinant enzymes showed Michaelis-Menten kinetics with a $K_{\mathrm{m}}$ of $158 \mu \mathrm{M} \mathrm{L}$-dopa for AADC (Fig. $2 u$ ), which is higher
Table 1. Activities of recombinant enzymes in genetically modified primary fibroblasts

\begin{tabular}{lclc} 
Tissues/cells & $\begin{array}{c}\text { TH activity } \\
(\mathrm{pmol} / \mathrm{mg} / \mathrm{min})\end{array}$ & Tissues/cells & $\begin{array}{c}\text { AADC activity } \\
\text { (pmol/mg/min) }\end{array}$ \\
\hline FF10/hTH & $508 \pm 84$ & FF2/AADC & $905 \pm 60$ \\
FF12/hTH & $265 \pm 2.5$ & FF12/AADC & $1160 \pm 50$ \\
Rat caudate & $1260 \pm 85$ & Rat caudate & $1300 \pm 105$
\end{tabular}

Numbers after FF indicate a particular biopsy sample of skin fibroblasts. The data are presented as mean $\pm \mathrm{SD}$. $\mathrm{FF} / \mathrm{hTH}$, primary fibroblasts modified to express human TH; FF/AADC, primary fibroblasts modified to express bovine AADC.

than the $K_{\mathrm{m}}$ of $14 \mu \mathrm{M}$ for native bovine adrenal AADC (Albert et al., 1987). The activities also depended on the supply of the cofactors, showing the most optimal AADC activity at a range of $10 \mu \mathrm{M}$ to $100 \mu \mathrm{M}$ PLP (Fig. 2b). At higher concentrations, the activity decreased due to substrate inhibition. Similar properties were noted for TH-transduced cells: $K_{\mathrm{m}}$ for tyrosine was 271 $\mu \mathrm{M}$ and the optimal $\mathrm{BH}_{4}$ concentrations were between 100 and $2000 \mu \mathrm{M}$.

The activity of AADC increased at $10 \mathrm{~d}$ after reaching confluent state. Northern blot analysis showed the expected $5.6 \mathrm{~kb}$ size message, which corresponds to the full retroviral transcript spanning both AADC and HPH coding regions (see Fig. 1). The relative amount of mRNAs estimated by densitometry showed that the ratio of AADC message to cyclophilin message increased from logarithmic growth phase to confluence (Table 2, Fig. 3).

Immunostaining of the cultured cells showed robust expression of AADC-immunoreactive proteins in the transduced cells (Fig. 4). There were some variations in the intensity of the staining of individual cells in this bulk-infected batch of primary fibroblasts. Even when clones were selected and grown as a homogeneous population, these variations in intensity were still noted (data not shown). FF/TH cells also showed positive immunoreactivity against TH antibody (data not shown).

In vitro production of catecholamines by genetically modified fibroblasts

The ability of these fibroblasts to produce and release catecholamines was studied in vitro. When FF2/AADC cells were incubated in the modified DMEM with $50 \mu \mathrm{M}$ L-dopa for varying lengths of time, there was a linear increase in dopamine through a $24 \mathrm{hr}$ period $\left(0.84 \mathrm{nmol} / \mathrm{hr} / 10^{6}\right.$ cells $)$ and a concomitant decrease in L-dopa levels in the medium. Metabolites of dopamine, such as homovanillic acid (HVA), 3,4-dihydroxyphenylacetate (DOPAC), and 3-methoxytyramine (3-MT), also increased with time after L-dopa administration (Fig. 5). When these cells were incubated with $0.5 \mathrm{~mm}$ of carbidopa, no detectable levels of dopamine and metabolites were noted and L-dopa levels stayed constant even after $24 \mathrm{hr}$ of incubation. This demonstrates the specificity of the enzymatic decarboxylation by AADC. Incubation of control noninfected fibroblast cells with up to $200 \mu \mathrm{M}$ concentrations of L-dopa for $24 \mathrm{hr}$ did not produce detectablc amounts of dopamine, 3-MT, HVA, DOPAC, or 3-O-methyldopa. The fact that $\mathrm{L}$-dopa levels remained nearly constant for $24 \mathrm{hr}$ also demonstrates the stability of L-dopa in the culture medium containing $0.01 \%$ ascorbic acid. The amount of dopamine in media was 20 times that inside cells after $6 \mathrm{hr}$, and the ratio of dopamine in the media to that in the cells increased to 132 after $24 \mathrm{hr}$ of incubation, suggesting low storage capacity 

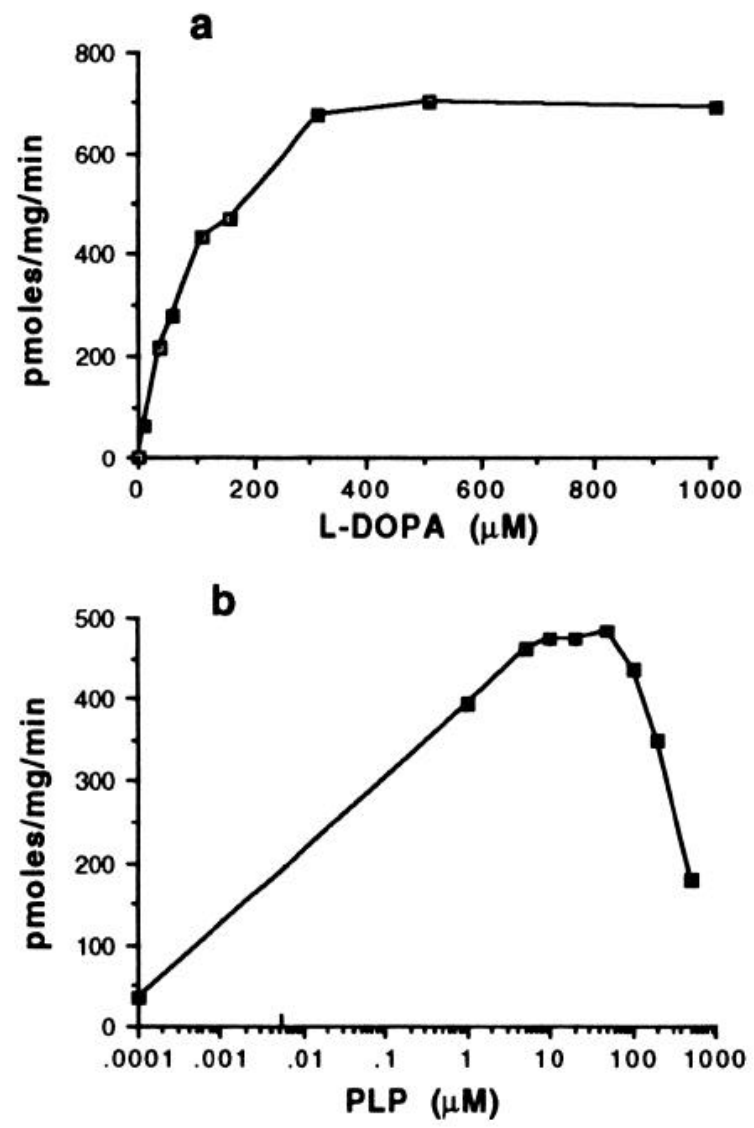

Figure 2. Kinetics of recombinant AADC. $a$, The kinetics of AADC toward the substrate L-dopa. The recombinant AADC has $K_{\mathrm{m}}$ of 158 $\mu \mathrm{M}$ using L-dopa as a substrate. $V_{\max }$ is $1 \mathrm{nmol} / \mathrm{mg} / \mathrm{min}$ of dopamine. $b$, The kinetics of AADC toward the cofactor PLP. The $\mathrm{x}$-axis is in logarithmic scale.

in these fibroblast cells. Likewise, the ratio of other metabolites in the media to cells was high, ranging from 21 (for DOPAC) to 164 (for 3-MT) after $6 \mathrm{hr}$ and 132 (DOPAC) to 279 (3-MT) after $24 \mathrm{hr}$.

Potassium depolarization was used to investigate the release mechanism of catecholamine, with a $55 \mathrm{~mm}$ concentration of $\mathrm{KCl}$ in the medium for $10 \mathrm{~min}$. The dopamine level in medium was $1.20 \mathrm{nmol}(\mathrm{SD} \pm 0.11)$ before addition of high potassium, $1.15 \mathrm{nmol}( \pm 0.12)$ during $\mathrm{KCl}$ stimulation, and unchanged at $1.15 \mathrm{nmol}( \pm 0.05)$ after $\mathrm{KCl}$ stimulation.

Table 2. AADC activity and message levels at logarithmic growth phase versus quiescence after reaching confluent state

\begin{tabular}{llll} 
& $\begin{array}{l}\text { Log growth } \\
\text { phase }\end{array}$ & $\begin{array}{l}\text { 10 d post- } \\
\text { confluence }\end{array}$ & $\begin{array}{l}\text { Ratio } \\
\text { (conf/ } \\
\text { log) }\end{array}$ \\
\hline $\begin{array}{c}\text { AADC activity } \\
\text { (nmol/mg/min) }\end{array}$ & $1.16 \pm 0.05$ & $2.12 \pm 0.11$ & 1.8 \\
$\begin{array}{c}\text { Ratio of AADC to cylcophilin } \\
\text { message (density units) }\end{array}$ & 0.43 & 1.0 & 2.3 \\
\hline
\end{tabular}

Parallel batches of cells were used for enzymatic activity and Northern blot analysis. Densitometry reading of the radiograph in the linear range was used to estimate the relative amounts of the messages as described in the text. Density of $3 \mathrm{hr}$ exposure of $5 \mu \mathrm{g}$ of total RNA lanes was used for the calculation.

\section{Log Cont Conf}

\section{AADC}

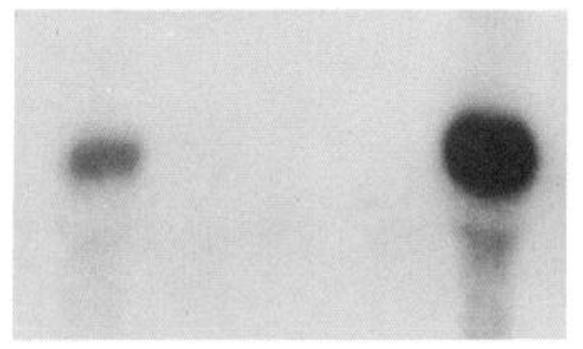

CYCLO

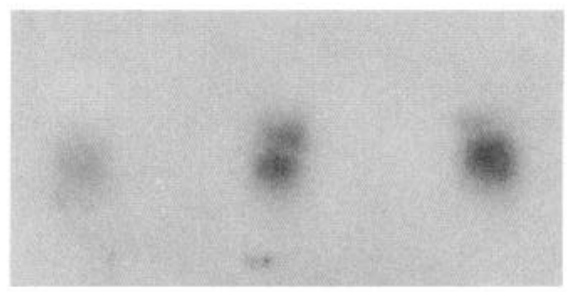

Figure 3. Northern blot analysis: Northern blot showing AADC message $(A A D C)$ at $\log$ growth phase $(\log )$ and at confluence $($ Conf $)$. Total RNA loaded in each lane was $5 \mu \mathrm{g}$ in this radiograph. The middle lane shows the RNAs from control untransduced cells (Cont). The bottom signals are for the cyclophilin (CYCLO) (see Table 2).

\section{Regulation of dopamine production from $F F / A A D C$ cells in culture by L-dopa administration}

The FF12/AADC fibroblasts were incubated in the modified DMEM supplemented with $0-200 \mu \mathrm{M}$ L-dopa for $20 \mathrm{hr}$. An approximately linear increase of the product dopamine was noted in media, when incubated with an increasing concentration of substrate L-dopa (Fig. 6). The metabolites also increased in a dose-dependent fashion. The catecholamines in the cell increased to an L-dopa concentration of $100 \mu \mathrm{M}$, but higher doses did not increase it any further. Again, the presence of carbidopa blocked dopamine production and maintained the L-dopa level without any decrease. Control cells without AADC did not produce any significant level of dopamine.

\section{Regulation of dopamine production by FF/AADC cells in culture by coculturing with $\mathrm{FF} / \mathrm{TH}$ cells}

When $2 \times 10^{5} \mathrm{FF} / \mathrm{TH}$ cells were incubated in the presence of tyrosine and $\mathrm{BH}_{4}$, they produced $174 \mathrm{nmol}$ of $\mathrm{L}$-dopa $/ \mathrm{hr} / \mathrm{mg}$ of cells, achieving about $20 \mu \mathrm{M}$ concentration in the medium after $20 \mathrm{hr}$ of incubation; no significant dopamine was detected. When $10 \%$ of FF/TH cells were replaced by FF/AADC cells, the L-dopa levels in the media dropped to about $50 \%$ of the level of cultures with $100 \%$ of $\mathrm{FF} / \mathrm{TH}$ cells; dopamine was produced and released to the media at a rate of $1.1 \mathrm{nmol} / \mathrm{hr} / \mathrm{mg}$. Increasing the proportion of FF/AADC cells to $25 \%$ and $33 \%$ in the culture and decreasing the proportion of $\mathrm{FF} / \mathrm{TH}$ to $75 \%$ and $67 \%$ further elevated the level of dopamine produced, and a higher proportion of FF/AADC in the mixed culture actually decreased the final output of dopamine (Fig. 7). Since the growth rates of FF/ TH and FF/AADC cells were comparable and the cells were plated at high densities to reach confluence by the next day, the proportions of the two types of cells at the time of media collection were assumed to be close to the plating ratio and were not determined specifically. 

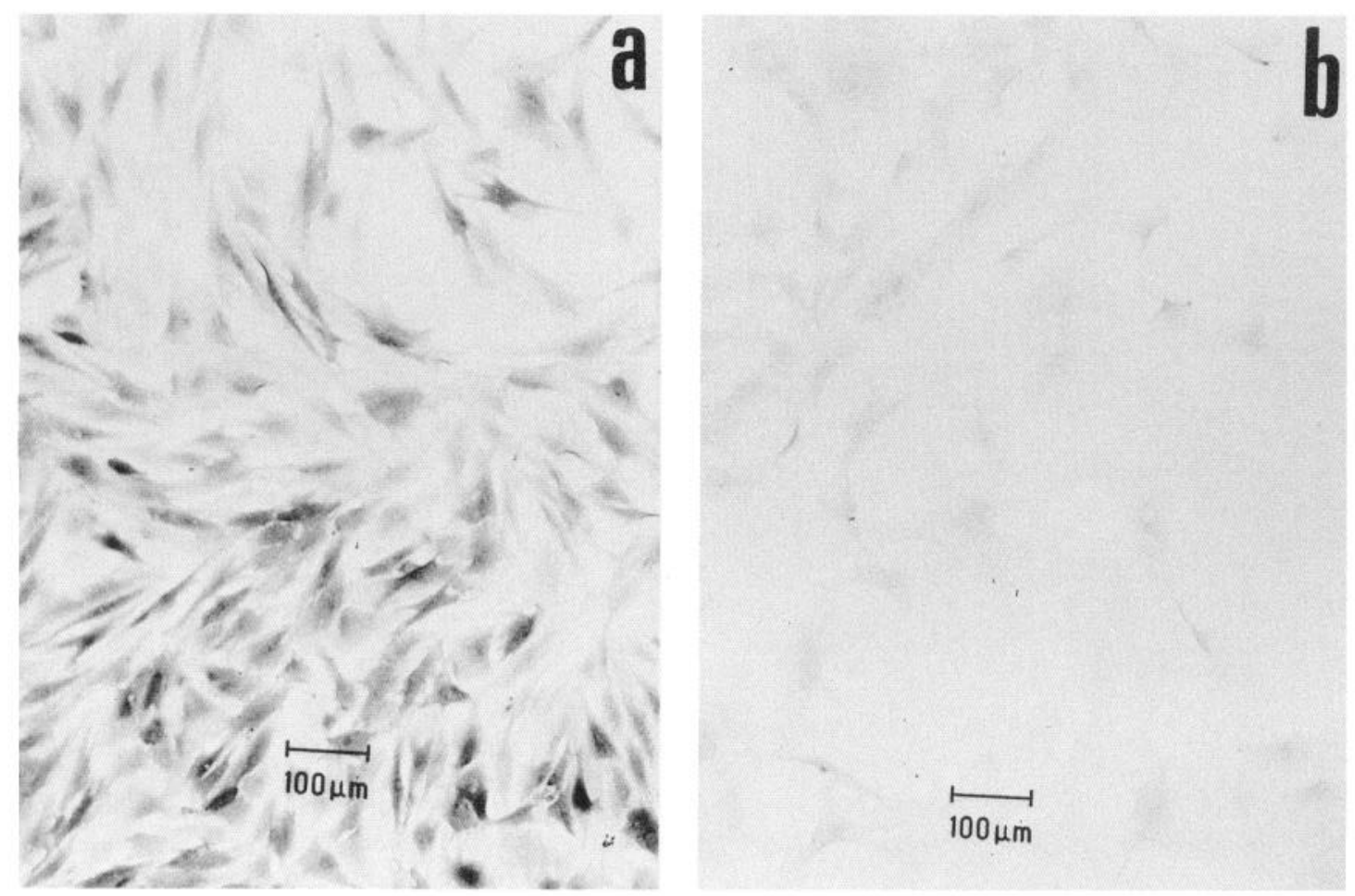

Figure 4. Immunocytochemistry of FF/AADC. a, Primary fibroblasts transduced with cDNA for AADC show immunoreactivity to AADC antibody. $b$, This panel shows the lack of AADC-immunoreactivity of untransduced, control fibroblasts.

\section{Discussion}

We demonstrated that full enzymatic activity of AADC can be expressed in primary fibroblast cells after transduction of a fulllength cDNA. The activities were of a similar order of magnitude in primary cultures of fibroblasts and in transformed fibroblast lines such as Rat 1 and $\Psi-2$ cells. These specific activities were also comparable to those seen in homogenates of rat caudate nucleus. AADC undergoes relatively little posttranslation processing, and the comparability of activities in transduced cells and in caudate suggests that AADC is sufficiently activated in fibroblast cells. Since the activity assay reflects the most optimal conditions for enzymatic activity, in vitro culture experiments were performed to see if these activities were still intact in the fibroblast cells and if the dopamine and metabolites were released from the cells. Catecholamine levels in cells and media indicated not only that dopamine is produced by these cells but also that the catecholamines trafficked in and out of the fibroblast cells easily. The levels in the media paralleled those in the cells, with respect to both the concentrations and the time spent in culture. There did not seem to be significant storage capacity in these cells, as reflected by the high ratio of catecholamines in the media to those in the cell pellet and by continuing accumulation of catecholamines in the media with little change in the cell pellet after longer incubation times, nor did potassium depolarization increase the release of the catecholamines. Both the high ratio and the lack of response to depolarization indicated the simple constitutive nature of the release process. Although storage capacity with regulation of the release process might be more desirable for eventual therapeutic applications, this constitutive secretory system allowed us to take advantage of the consistently high level of catecholamine release by these genetically modified fibroblast cells and to use them as biological minipumps. The simple and efficient release process also enabled us to devise cocultures of the FF/TH and FF/AADC cells, since the L-dopa formed by the FF/TH cells easily diffuses out of the $\mathrm{FF} / \mathrm{TH}$ cells and into FF/AADC cells for subsequent metabolic steps. The independent mixture of TH and AADC system permitted more systematic studies of the relative role of TH and AADC in dopamine production than can be achieved without cells that contain both TH and AADC in a fixed proportion.

We have employed the retrovirus-mediated gene transfer technique because of the low efficiency of transfection methods in primary cells. Since primary fibroblast cells have a limited number of doublings in culture before manifesting senescence, bulk-infected populations of primary fibroblasts were used for our experiments. This necessarily increases the potential for problems in the mixed population of cells. Some of the cells may produce mutant products of the transgene from rearrangement of the inserted gene. Random integration of the retroviral vector into the host genome can also produce insertional mutation with alteration of growth properties resulting in tumor formation. We have not noticed tumor formation with passages up to $24 \mathrm{hr}$ in culture or in any of the grafting experiments, but one must be alerted to the possibility in applying this technique to clinical situations.

Characteristics of the genetically modified fibroblasts suggested several potential ways of regulating the level of dopamine produced by these cells. The level of transcription and translation of the transgene may not be easily manipulated with the present construct driven by the retroviral LTR promoter. Further understanding of promoter activity regulation, transcript stability, and translation efficiency is necessary. Transcription and translation can also be influenced by the growth phase and host environment of the fibroblast graft. We have previously 

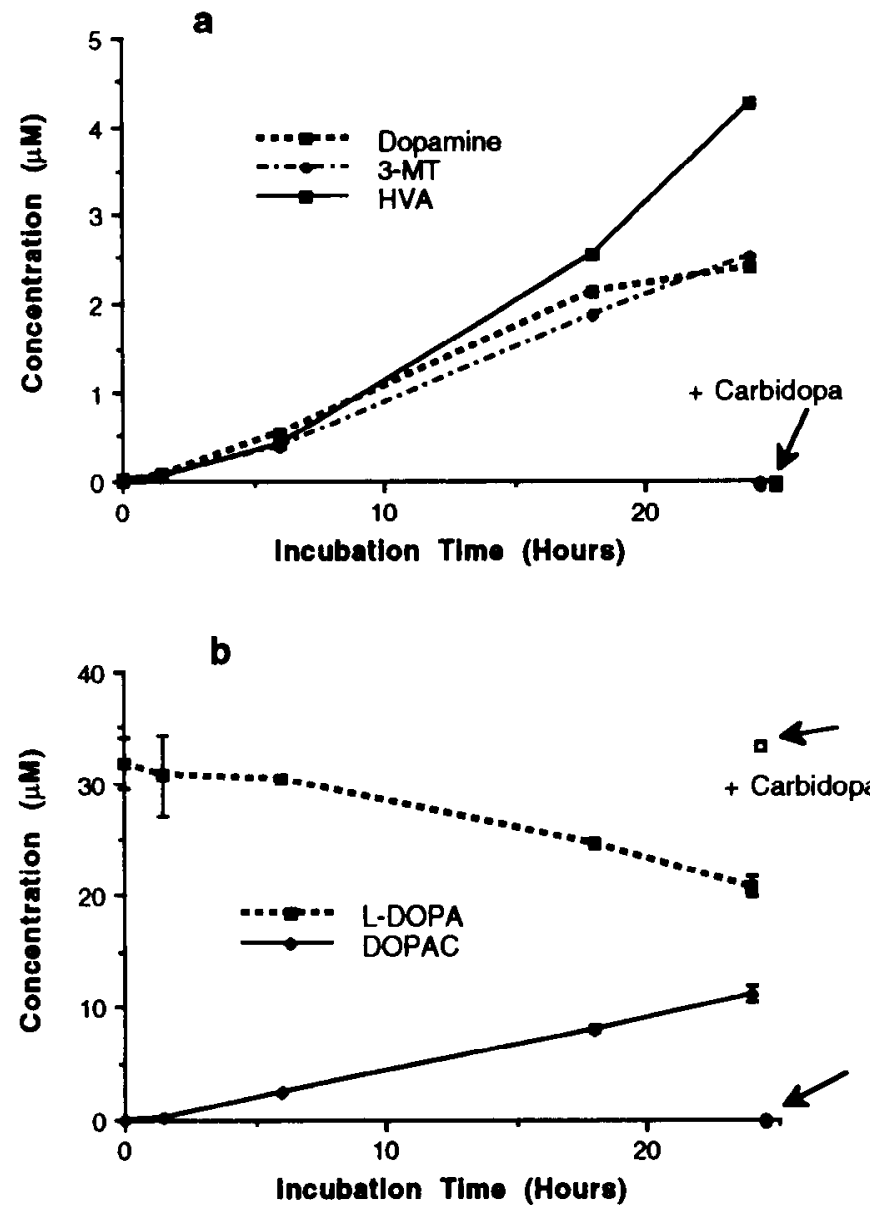

Figure 5. Time course of L-dopa incubation. FF2/AADC cells were incubated in DMEM (contains $24 \mu \mathrm{M}$ pyridoxal $\mathrm{HCl}$ ) with $10 \%$ fetal calf serum and $50 \mu \mathrm{M}$ L-dopa in $0.01 \%$ ascorbic acid solution at various durations. Dopamine $(a)$ in media increased linearly with time with corresponding increases in metabolites 3-MT $(a)$, HVA $(a)$, and DOPAC (b). The L-dopa concentration in the media decreased linearly with time (b). When the AADC inhibitor carbidopa was added to the $24 \mathrm{hr}$ culture (arrow), no detectable levels of dopamine or other metabolites were noted (the symbols are all clustered together on the $\mathrm{x}$-axis in $a$ ) and consumption of L-dopa was totally blocked (in $b$ ). The data represent a mean of three separate samples, and the vertical bars indicate SEM (many of the error bars are not visible because they are smaller than the symbols).

studied two conditions in culture that may reflect conditions of the fibroblasts in vivo: serum starvation and quiescence from confluence. Serum starvation decreased activities and steady state levels of mRNAs of both transgene and cyclophilin, a constitutive enzyme used as a marker of the general metabolic status of the cells. The state of quiescence achieved in vivo after grafting is reflected in the contact inhibition of the fibroblast cell growth after reaching confluence. Confluence reduced activity and steady state levels of mRNA of a transgene, ChAT, relative to those of cyclophilin in culture of Rat 1 fibroblasts transduced with ChAT cDNA (Schinstine et al., 1992). However, AADC-transduced primary skin fibroblast cells showed increases in the enzymatic activity and message after confluence. Stability at the level of protein cannot explain the differences since mRNA levels are also increased. Therefore, the nature of the transgene may influence the promoter activity or, more likely, the mRNA stability. Better mRNA stability may lead to prolonged presence of the message, thereby increasing the steady state levels.

At the biochemical level, the substrate concentrations and cofactor concentrations are the most critical parameters in determining the final dopamine production. These can be varied by supplying external sources, as demonstrated by our in vitro assays and culture studies. Both substrates and cofactors have optimal ranges; the substrate effect saturates beyond the $K_{\mathrm{m}}$ values and the cofactor shows inhibition of activity at too high a concentration. Since PLP is thought to be present in many cell types, the critical factor in the final dopamine production is the concentration of L-dopa. This can be controlled by exogenous administration, as is done in patients with PD. Cografting with $\mathrm{FF} / \mathrm{TH}$ cells provides the precursor endogenously in the graft, and the level of precursor can be controlled by the ratio of FF/TH to FF/AADC cells within the graft. One of the essential findings from in vitro incubation studies was that the catecholamines, L-dopa, and dopamine diffuse in and out of the cells easily, allowing the FF/AADC cells to utilize the L-dopa produced by FF/TH cells. These approaches were explored in our experiments and will be discussed in more detail below. The regulation at the level of release may not be significant in fibroblasts, as noted by the high ratio of the catecholamines in the media to cell pellets, nor could these cells serve as a storage mechanism for the dopamine formed.

Our study focused on transgene regulation at the biochemical level, which is relatively better understood than other levels of regulatory steps discussed above. Specifically, we constructed genetically modified cells that express the last enzymatic step of dopamine synthesis. These FF/AADC cells serve as additional sources of dopa decarboxylation and may increase the efficacy of L-dopa treatment. One of the basic unresolved issues in the neurotransmitter replacement therapy of PD is how the L-dopa is decarboxylated to dopamine in the denervated striatum. Despite the loss of the majority of dopaminergic neurons in rats with 6-hydroxydopamine lesions of the substantia nigra, L-dopa is still converted to dopamine (Hefti et al., 1981). The same is true in patients with PD, as demonstrated by the efficacy of the treatment with L-dopa. Microdialysis studies in the denervated striatum after infusion of exogenous L-dopa have shown that dopamine levels in the extracellular space of denervated striatum is either comparable to (Zetterstrom et al., 1986) or higher than (Abercrombie et al., 1990) the level of dopamine produced in the intact striatum. These findings have been attributed to two factors in the denervated striatum: significant residual dopa-decarboxylating activity and lack of reuptake of released dopamine. Despite the loss of greater than $95 \%$ of dopamine and $\mathrm{TH}$ activity in the denervated striatum, about $15-20 \%$ of dopa-decarboxylating activity remains (Melamed et al., 1981). Most of this dopa decarboxylation is catalyzed by AADC without significant contribution by nonenzymatic decarboxylation or other enzymes (Kang et al., 1992). The source and site of this remaining AADC in dopamine-depleted animals are not clear. Some researchers have suggested that 5-HT terminals provide an alternative source of AADC (Duvoisin and Mytilineou, 1978), but others noted that the contribution by this system is not significant (Melamed et al., 1980, 1981). Some investigators have proposed that intrinsic striatal neurons were the source of AADC, on the basis of biochemical data (Melamed et al., 1981), but others did not detect AADC in striatal neurons with in situ hybridization and immunocytochemistry (Jeager et al., 1984; Kang ct al., 1992). Dopa decarboxylation may not 

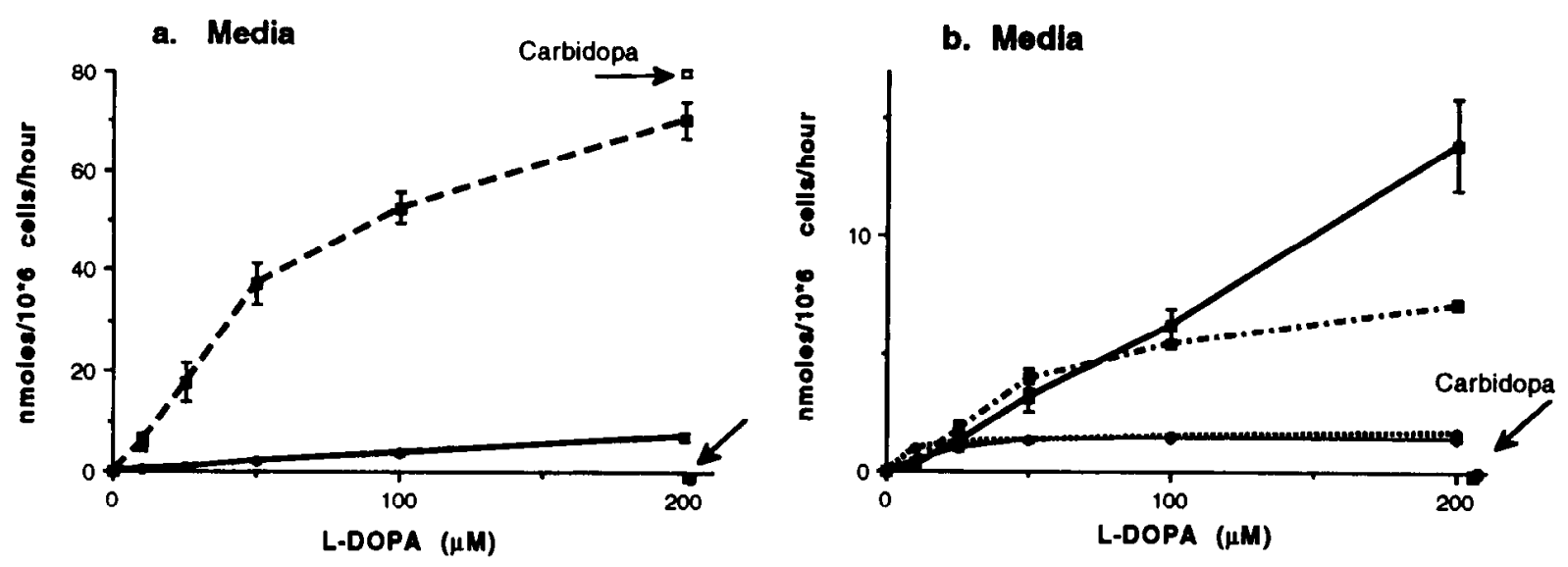

c. Cell Pellet

d. Cell Pellet
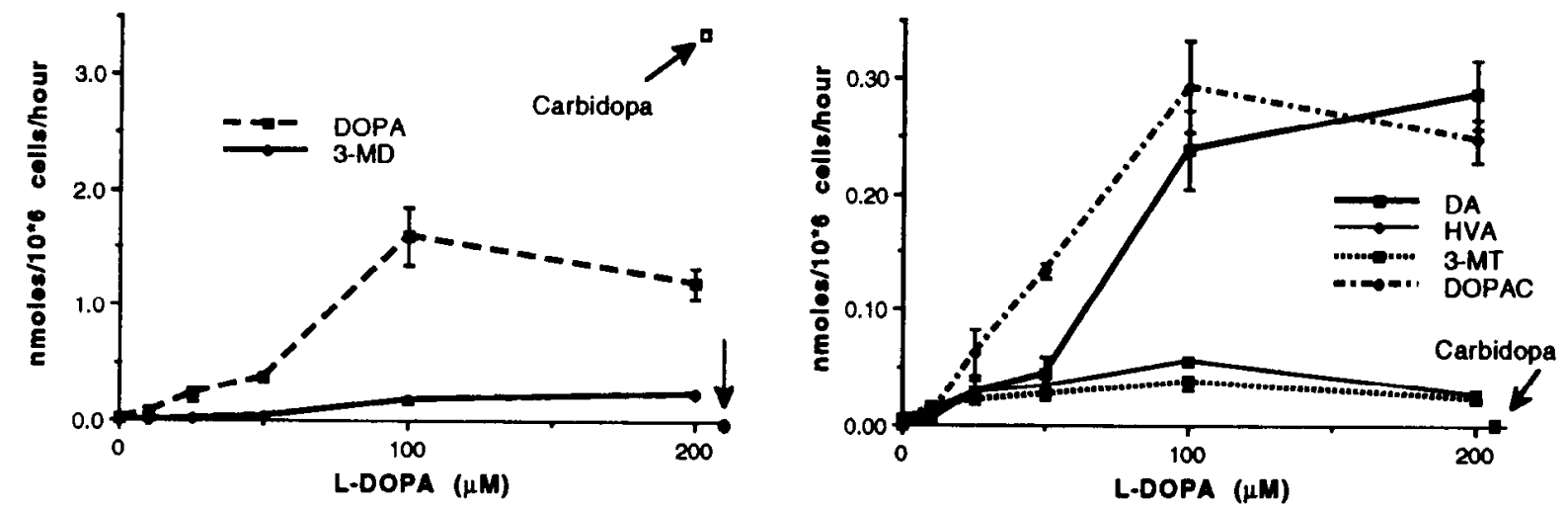

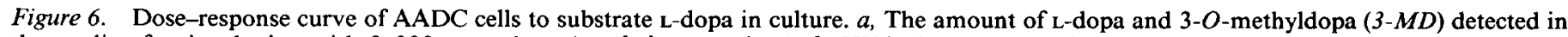

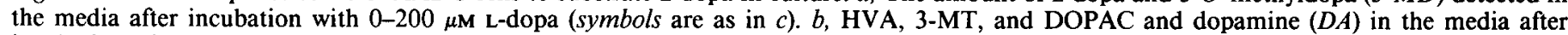

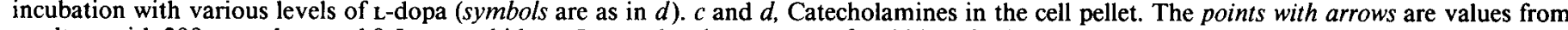

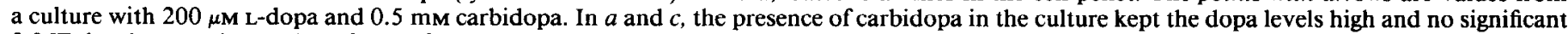

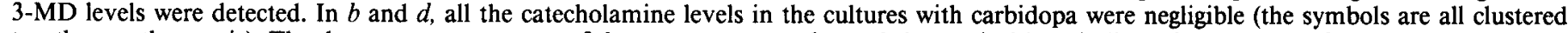

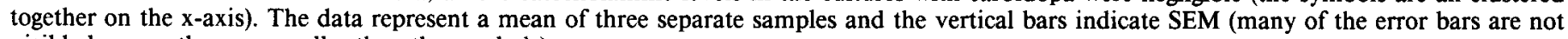
visible because they are smaller than the symbols).

occur in the striatum itself; dopamine may be formed in other nearby areas and diffuse back into the striatum. In the absence of a dopamine uptake system in the dopaminergic terminals, dopamine may remain in the extracellular space without being removed and could diffuse to a longer distance. This lack of inactivation by the uptake system has been thought to be responsible for the high extracellular dopamine level seen in $\mathrm{mi}$ crodialysis studies in denervated striatum. Whether residual AADC provides optimal dopa-decarboxylating capacity or whether the efficiency could be improved by addition of AADC is not resolved either. As the dopaminergic cell loss progresses, there may not be enough dopa decarboxylation capacity left in the denervated striatum. Melamed (1988) has suggested that the reason fetal grafting is effective is not because the graft provides dopamine directly but because it provides AADC, which increases the efficiency of L-dopa therapy. This may explain why dopaminergic transplants to PD patients so far have been able to reduce $\mathrm{I}$-dopa doses but have not been able to eliminate the need for the medication entirely (Freed et al., 1992; Spencer et al., 1992). We can test this hypothesis on the role of AADC directly by grafting AADC-expressing cells in the denervated striatum and administering L-dopa systemically. Moreover, if the affinity of the recombinant AADC for the substrate $L$-dopa is higher than that of the endogenous AADC, a low dose of L-dopa may be effective in producing dopamine within the grafts and releasing it locally in the striatum at high levels while not producing significant dopamine in other areas. This may allow us to reduce the risk of side effects of systemic administration, such as psychosis, and fluctuating responses such as dyskinesias. Psychosis is probably related to stimulation of the dopamine receptors in the limbic system (Moskovitz et al., 1978). Some have suggested that the site of dyskinesia may be in the substantia nigra (Orosz and Bennett, 1992). Therefore, a more localized delivery of dopamine may be able to avoid the side effects associated with the systemic treatment.

Another area that AADC-transduced cells are useful as catecholamine sources is in comparing the effect of dopamineproducing grafts with that of L-dopa-producing grafts. One study (Horellou et al., 1990a) attempted to address the question of whether grafting cells that produce dopamine is more or less effective in delivering dopamine throughout the striatum than grafting cells producing L-dopa. These researchers found that L-dopa-producing grafts produced more effective behavioral reversal and resulted in higher dopamine levels in the striatum than dopamine-producing grafts. This study, however, used two different cell types, one with $\mathrm{TH}$ transduced into a fibroblast 

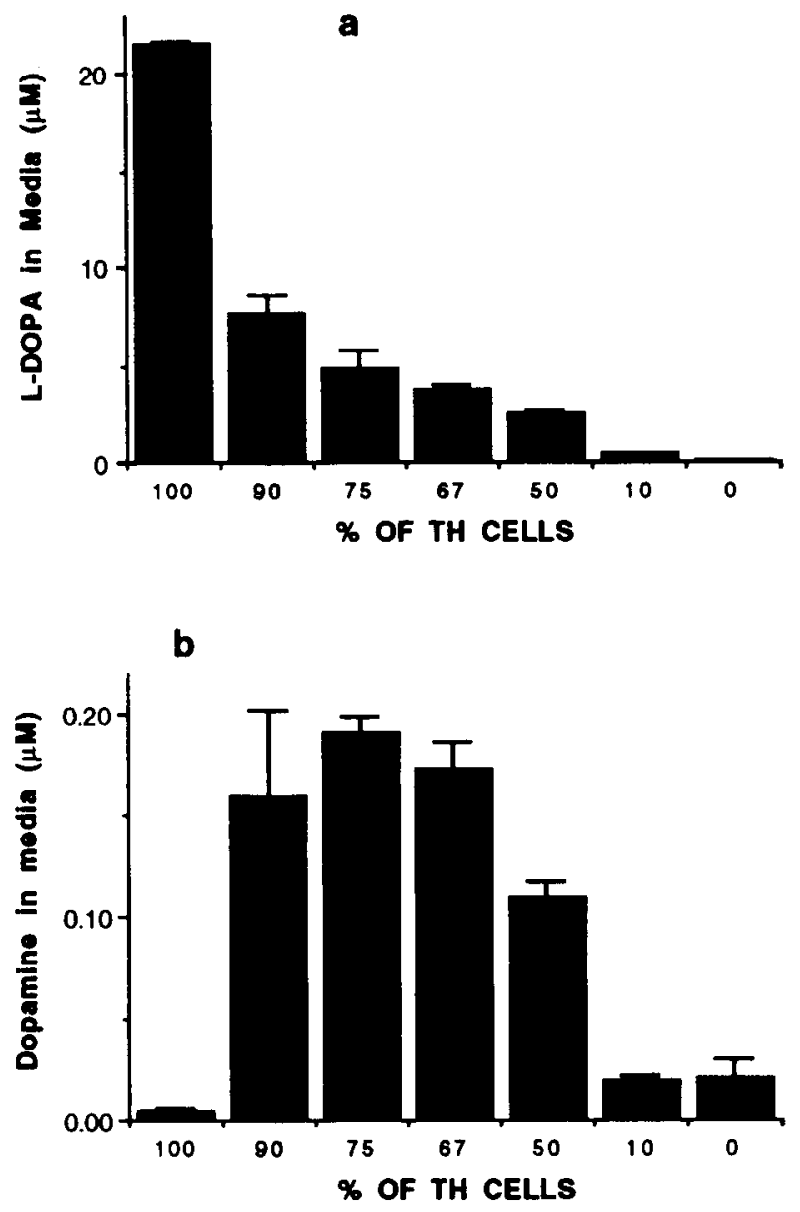

Figure 7. Coincubation of FF/TH and FF/AADC. The $y$-axis shows the concentration of $\mathbf{L}$-dopa $(a)$ and dopamine $(b)$ in the media after 20 $\mathrm{hr}$ in culture. The $x$-axis shows the percentage of FF/TH cells in the total mixture of cells in the culture at the time of the plating. The rest of the cells in the culture are FF/AADC cells. The vertical bars indicate SEM.

cell line and the other with $\mathrm{TH}$ transduced into an endocrine cell line with endogenous AADC expression. Inspection of the data reveals that the levels of TH activity after transduction in these two cell lines and the survival and growth of the two cell lines after grafting are not the same. Therefore, the higher level of dopamine produced in the host striatum by the L-dopa-producing grafts may have reflected the higher TH activity and, hence, the higher level of initial L-dopa production. Reversal of apomorphine-induced rotations could also have been affected by the larger graft size of the L-dopa-producing cells and other variables of the cell type. We can compare the effect of dopamine delivery with L-dopa delivery using a more controlled approach involving a fibroblast system that has separate TH- and AADCtransduced cells. Grafts consist of either TH-transduced fibroblast cells mixed with control fibroblast cells or TH-transduced fibroblast cells mixed with AADC-transduced fibroblast cells. This protocol assures the comparability, in any given experiment, of the graft size, cell number, and total TH activity in the two groups, with the only difference being the presence or absence of AADC. Our coculture data indicate the feasibility of this approach and suggest the optimal ratio of $\mathrm{FF} / \mathrm{TH}$ to $\mathrm{FF}$ / AADC cells to be grafted to achieve the maximal possible production of dopamine in the graft. Detailed biochemical characterization of these FF/TH and FF/AADC cells allows us to approach the grafting experiments more systematically by mixing the two cell types for optimal production of dopamine.

Our study attempted to elucidate the role of AADC in the production of dopamine by genetically modified donor cells. Further, we have demonstrated the utility of AADC-transduced cells in regulating the dopamine delivery by supplying exogenous precursors or coculturing with cells that produce an endogenous source of precursors. In the future, the role of AADC in increasing the delivery of dopamine will have to be established in vivo. The exact amount of the catecholamines delivered and the functionally useful level of catecholamine need to be determined in future studies using animal models of PD.

\section{References}

Abercrombie ED, Bonatz AE, Zigmond MJ (1990) Effects of L-dopa on extracellular dopamine in striatum of normal and 6-hydroxydopamine-treated rats. Brain Res 525:36-44.

Albert VR, Allen JM, Joh TH (1987) A single gene codes for aromatic L-amino acid decarboxylase in both neuronal and non-neuronal tissues. J Biol Chem 262:9404-9411.

Bostwick JR, Le W-D (1991) A tyrosine hydroxylase assay in microwells using coupled nonenzymatic decarboxylation of dopa. Anal Biochem 192;1-6.

Cotzias GC, Papavasiliou PS, Gellene R (1969) Modification of parkinsonism: chronic treatment with L-dopa. N Engl J Med 280:337345.

Dunnett SB, Hernandez TD, Summerfield A, Jones GH, Arbuthnott G (1988) Graft-derived recovery from 6-OHDA lesions: specificity of ventral mesencephalic graft tissues. Exp Brain Res 71:411-424.

Duvoisin RC, Mytilineou C (1978) Where is L-dopa decarboxylated in the striatum after 6-hydroxydopamine nigrotomy? Brain Res 152: 369-373.

Fine A (1990) Transplantation of adrenal tissue into the central nervous system. Brain Res Rev 15:121-133.

Fisher LJ, Jinnah HA, Kale LC, Higgins GA, Gage FH (1991) Survival and function of intrastriatally grafted primary fibroblasts genetically modified to produce L-dopa. Neuron 6:371-380.

Freed CR, Breeze RE, Rosenberg NL, Schneck SA, Kriek E, Qi J-X, Lone T, Zhang Y-B, Snyder JA, Wells TH, Ramig LO, Thompson L, Mazziotta JC, Huang SC, Grafton ST, Brooks D, Sawle G, Schroter G, Ansari AA (1992) Survival of implanted fetal dopamine cells and neurologic improvement 12 to 46 months after transplantation for Parkinson's disease. N Engl J Med 327:1549-1555.

Freed WJ, Patel-Vaidya U, Geller HM (1986) Properties of PC12 pheochromocytoma cells transplanted to the adult rat brain. Exp Brain Res 63:557-566.

Freed WJ, Poltorak M, Becker JB (1990) Intracerebral adrenal medulla grafts: a review. Exp Neurol 110:139-166.

Gage FH (1990) Intracerebral grafting of genetically modified cells acting as biological pumps. Trends Pharmacol Sci 11:437-439.

Gage FH, Kang UJ, Fisher LJ (1991a) Intracerebral grafting in the dopaminergic system: issues and controversy. Curr Opin Neurobiol $1: 414-419$.

Gage FH, Kawaja MD, Fisher LJ (1991b) Genetically modified cells: applications for intracerebral grafting. Trends Neurosci 14:328-333.

Graham FL, Van Der Eb AJ (1973) A new technique for the assay of infectivity of human adenovirus 5 DNA. Virology 52:446-467.

Hefti F, Melamed E, Wurtman RJ (1981) The site of dopamine formation in rat striatum after $\mathrm{L}$-dopa administration. J Pharmacol Exp Ther 217:189-197.

Horellou P, Brundin P, Kalen P, Mallet J, Bjorklund A (1990a) In vivo release of dopa and dopamine from genetically engineered cells grafted to the denervated rat striatum. Neuron 5:393-402.

Horellou P, Marlier L, Privat A, Mallet J (1990b) Behavioral effect of engineered cells that synthesize L-dopa or dopamine after grafting into the rat neostriatum. Eur J Neurosci 2:116-119.

Jeager CB, Ruggiero DA, Albert VR, Joh TH, Reis DJ (1984) Immunocytochemical localization of aromatic $\mathrm{L}$-amino acid decarboxylase. In: Handbook of chemical neuroanatomy, Vol 2 (Bjorklund A, Hökfelt T, eds), pp 387-408. Amsterdam: Elsevier.

Jellinger K (1987) The pathology of parkinsonism. In: Movement 
disorders 2 (Marsden CD, Fahn S, eds), pp 124-165. London: Butterworths.

Kang UJ, Joh TH (1990) Deduced amino acid sequence of bovine aromatic L-amino acid decarboxylase: homology to other decarboxylases. Mol Brain Res 8:83-87.

Kang UJ, Park DH, Wessel T, Baker H, Joh TH (1992) Dopa-decarboxylation in the striata of rats with unilateral substantia nigra lesions. Neurosci Lett 147:53-57.

Kawaja MD, Gage FH (1992) Morphological and neurochemical features of cultured primary skin fibroblasts of Fischer-344 rats following striatal implantation. J Comp Neurol 317:102-116.

Kurlan R, Nutt JG, Woodward WR, Rothfield K, Lichter D, Miller C, Carter JH, Shoulson I (1988) Duodenal and gastric delivery of levodopa in parkinsonism. Ann Neurol 23:589-595.

Lamprecht F, Coyle JT (1972) Dopa decarboxylase in the developing rat brain. Brain Res 41:503-506.

Mann R, Mulligan RC, Baltimore D (1983) Construction of a retrovirus packaging mutant and its use to produce helper-free defective retrovirus. Cell 33:153-159.

Marsden CD, Parkes JD (1977) Success and problems of long-term levodopa therapy in Parkinson's disease. Lancet i:345-349.

Melamed E (1988) Brain grafting may reverse loss of responsiveness to levodopa therapy in Parkinson's disease. Clin Neuropharmacol 11: 77-82.

Melamed E, Hefti F, Liebman J, Schlosberg AJ, Wurtman RJ (1980) Serotonergic neurons are not involved in action of $\mathbf{L}$-dopa in Parkinson's disease. Nature 283:772-774.

Melamed E, Hefti F, Pettibone DJ, Liebman J, Wurtman RJ (1981) Aromatic L-amino acid decarboxylase in rat corpus striatum: implications for action of $\mathrm{L}$-dopa in parkinsonism. Neurology 31:651-655.

Miller AD, Buttimore C (1986) Redesign of retrovirus packaging cell lines to avoid recombination leading to helper virus production. Mol Cell Biol 6:2895-2902.

Moskovitz C, Moses H III, Klawans HL (1978) Levodopa-induced psychosis: a kindling phenomenon. Am J Psychiatry 135:6.
Nutt JG (1990) Levodopa-induced dyskinesia: review, observations, and speculations. Neurology 40:340-345.

Orosz D, Bennett JP (1992) Simultaneous microdialysis in striatum and substantia nigra suggests that the nigra is a major site of action of L-dihydroxyphenylalanine in the "hemiparkinsonian" rat. Exp Neurol 115:388-393.

Quinn N, Parkes JD, Marsden CD (1986) Control of on/off phenomenon by continuous intravenous infusion of levodopa. Neurology 34 : 1131-1136.

Sambrook J, Fritsch EF, Maniatis T (1989) Molecular cloning: a laboratory manual. Cold Spring Harbor, NY: Cold Spring Harbor Laboratory.

Schinstine M, Rosenberg MB, Routledgeward C, Friedmann T, Gage FH (1992) Effects of choline and quiescence on Drosophila choline acetyltransferase expression and acetylcholine production by transduced rat fibroblasts. J Neurochem 58:2019-2029.

Spencer DD, Robbins RJ, Naftolin F, Marek KL, Vollmer T, Leranth C, Roth RH, Price LH, Gjedde A, Bunney BS, Sass KJ, Elsworth JD, Kier EL, Makuch R, Hoffer PB, Redmond DE, Jr (1992) Unilateral transplantation of human fetal mesencephalic tissue into the caudate nucleus of patients with Parkinson's disease. N Engl J Med 327:15411548

Sweet RD, McDowell FH, Feigenson JS, Loranger AW, Goodell H (1976) Mental symptoms in Parkinson's disease during chronic treatment with levodopa. Neurology 26:305-310.

Waymire JC, Bjur R, Weiner N (1971) Assay of tyrosine hydroxylase by coupled decarboxylation of dopa formed from $1-{ }^{14} \mathrm{C}-\mathrm{L}$-tyrosine. Anal Biochem 43:588-600.

Zetterstrom T, Herrera-Marschitz M, Ungerstedt U (1986) Simultaneous measurement of dopamine release and rotational behaviour in 6-hydroxydopamine denervated rats using intracerebral dialysis. Brain Res 376:1-7. 